\title{
Un panorama por el audiovisual aragonés en la década de los años ochenta
}

Fernando Sanz Ferreruela ${ }^{1}$

Cuando en 1983, tras las I Jornadas Culturales del Cómic impulsadas por Antonio Altarriba el año anterior, apareció el primer número de la revista Neuróptica, el panorama en el que se encontraban las artes audiovisuales y las llamadas «artes de masas» en nuestro país, puede definirse como una verdadera encrucijada.

La reciente Transición a la democracia que operó la definitiva apertura cultural y artística, los nuevos usos y gustos sociales, las nuevas dinámicas de consumo cultural, y los nuevos hábitos de ocio que, por ejemplo, dieron al cómic un empuje extraordinario, marcaron una tendencia y una situación absolutamente inédita, que en el caso que aquí nos ocupa, tuvo una enorme repercusión en el panorama cinematográfico, y por extensión, en el ámbito audiovisual.

No hay que olvidar que en aquellos momentos la cinematografía española comenzaba a experimentar los efectos de una nueva política fílmica (ratificada con la promulgación de la «Ley Miró» a finales de 1983) que determinó un descenso en el volumen de producción cinematográfica en nuestro país, y por tanto una crisis abierta en el cine más «comercial», pero que por otro lado apuntaló la llamada producción de «calidad», circunstancia que se vio plasmada en la aparición de películas de la talla de La colmena (Mario Camus, 1982), y de algunos grandes éxitos a nivel internacional, como el de Volver a empezar (José Luis Garci, 1983), ganadora del primer Oscar de Hollywood para una película española. Fue también el momento del surgimiento de la «nueva comedia madrileña», que contó con títulos paradigmáticos como Opera prima (Fernando Trueba, 1980) o La vida alegre (Fernando Colomo, 1987), y de los primeros compases del «fenómeno» Almodóvar, que en estos años rodó Laberinto de pasiones (1982), Entre tinieblas (1983) y ¿Qué he hecho yo para merecer esto? (1984). A pesar de todo ello,

1 Universidad de Zaragoza. Este texto se enmarca en el proyecto: Estudio de la cultura audiovisual del tardofranquismo (1970-1975). Proceso de modernización y transiciones en cine, fotografía, televisión, cómic y diseño. (HAR2017-88543-P), financiado por el Ministerio de Ciencia, Innovación y Universidades y desarrollado en la Universidad de Zaragoza. Investigadora principal: Amparo Martínez Herranz. 
tampoco hay que perder de vista que los primeros años ochenta vinieron determinados por una gran crisis en el ámbito de la exhibición, sobre todo para el cine español, caída de público que se vio agudizada por el arranque definitivo del video y el gran auge de la televisión en nuestro país. ${ }^{2}$

Y por lo que se refiere al contexto aragonés y particularmente zaragozano, estos fenómenos tuvieron lugar en un momento, marcado por un lado por el continuismo en muchas circunstancias, pero en el que se estaba asistiendo, como veremos, a una verdadera renovación que marcó un antes y un después en el panorama audiovisual.

\section{EL TRABAJO DE LOS CINEASTAS ARAGONESES (FUERA DE ARAGÓN) EN EL ÁMBITO PROFESIONAL}

En primer lugar, en cuanto al panorama de la producción de cine en el ámbito profesional, cabe lamentar que la situación en la que se encontraba la ciudad de Zaragoza no podía ser más crítica. Así, podemos afirmar que tras el frustrado episodio que supuso Moncayo Films entre 1961 y 1968, 3 la industria cinematográfica había dejado de existir en la capital del Ebro, y en todo Aragón.

Sin embargo, los años ochenta fueron un momento de máxima importancia en las carreras de muchos de los cineastas aragoneses (sobre todo zaragozanos y algún oscense) que fuera de nuestras fronteras estaban llevando a cabo una tarea envidiable.

José Luis Borau, por su parte, desde su productora El Imán, y tras un paréntesis de cinco años tras su anterior película La sabina (1979), en 1984 escribió, produjo y dirigió la coproducción hispano-norteamericana Río abajo, protagonizada por la peculiar pareja de actores formada por David Carradine y Victoria Abril. Una arriesgada y ambiciosa apuesta que sin embargo no cosechó el éxito que su director hubiera deseado, pero que se vio recompensada en 1986 con Tata mía, protagonizada por Carmen Maura, y en

2 Para profundizar en el contexto del cine español de este periodo ver: RIAMBAU, E., «El periodo "socialista"» en., GUBERN, R., et al., Historia del cine español, Madrid, Cátedra, 2006, pp. 399-454, y BENET, V., El cine español. Una historia cultural, Barcelona, Paidós, 2012, pp. 396-400.

3 Perez, P. y Hernandez, J., Moncayo Films: una aventura de producción cinematográfica, Zaragoza, Institución Fernando el Católico-Ayuntamiento de Zaragoza, 1996, y DucE, J. A., La década de Moncayo Films, Zaragoza, Ayuntamiento de Zaragoza, 1997. 
la que se recuperó para la pantalla española a la ya crepuscular, pero siempre espontánea, Imperio Argentina. ${ }^{4}$

En otro orden de cosas, la de 1980 fue una fecha crucial en la evolución de la carrera de Carlos Saura, quien en ese momento estaba ya desterrando de su práctica fílmica esa «primera vía» del cine español, marcada por su talante metafórico e intelectual, característico de sus películas de los años setenta y de la época de la Transición, siempre a las órdenes del productor Elías Querejeta. Y ello para ir retornando hacia los postulados del realismo social, con Deprisa, deprisa, con la que ganó el Oso de Oro en el Festival de Berlín de ese año (a vueltas de nuevo con los temas del desarraigo juvenil con los que Saura inaugurara su carrera cinematográfica en el, ya lejano por entonces, año de 1958), para enseguida internarse en la que sería su nueva inquietud por el cine musical, de la mano del productor Emiliano Piedra, combinando a veces ficción y documental, con la trilogía interpretada por Antonio Gades, formada por Bodas de sangre (1981), Carmen (1983) y El amor brujo (1986). Mientras tanto, haciendo gala de su eclecticismo habitual en las últimas décadas, Saura empezó a combinar su cine musical con la última película rodada para Elías Querejeta, Las dulces horas (1982), explorando otras opciones, entre las que destacan sus primeras experiencias latinoamericanas en Antonieta (1982) y, sobre todo, la superproducción El dorado (1988), con la que además se internó en el cine histórico, tendencia que se prolongó en la apasionante reseña metafórico-biográfica sobre San Juan de la Cruz que constituye La noche oscura (1989) y su nueva revisión sobre la Guerra Civil española que supuso ¡Ay, Carmela! (1990). ${ }^{5}$

Otro zaragozano de nacimiento, José María Forqué, verdadero camaleón cinematográfico y magnífico artesano de la pantalla, tras rodar en los años setenta un cine alimenticio marcado por la presencia del cine de «sugerencia» sexual, en la década que nos ocupa cambió de registro hacia un género de plena actualidad y auge en ese momento que fue el de las series para televisión. Dentro del mismo, fue muy habitual por un lado la adaptación de obras literarias célebres (Fortunata y Jacinta, 1980, o La barraca, 1986, fueron dos de las más exitosas) y por otro lado los recorridos biográficos acerca de

4 Sobre este autor consultar HeREDERo, C. F., José Luis Borau. Teoría y prácticas de un cineasta, Madrid, Filmoteca Española, 1990; SANCHEz VidAL, A., Borau, Zaragoza, CAI, 1990 y SANCHEz SALAS, B., José Luis Borau. La vida no da para más, Madrid, Pigmalión Ediciones, 2012.

5 En cuanto a esta etapa de la filmografía de Saura, puede verse: SANCHEz VidAL, A., El cine de Carlos Saura, Zaragoza, CAI, 1988; SAnchez Millan, A., Carlos Saura, Huesca, Diputación Provincial de Huesca, 1991 y LefERE, R. (ed.), Carlos Saura, una trayectoria ejemplar, Madrid, Visor Libros, 2011. 
personajes célebres de nuestro pasado. ${ }^{6}$ Pues bien, en este último ámbito, y concretamente sobre personajes de origen aragonés, ${ }^{7}$ es en el que se internó Forqué, realizando series entre las que destacan sin duda las magníficas Ramón y Cajal (1982) y Miguel Servet, la sangre y la ceniza (1989), para TVE.

Precisamente en este campo televisivo (alternándolo a veces con otros trabajos puramente fílmicos) no puede dejar de citarse otro numeroso grupo de autores aragoneses ${ }^{8}$ que trabajaron en los ochenta, como Alfredo Castellón, que hizo para TVE varios Estudio 1, y el largometraje Las gallinas de Cervantes (1988), o José Antonio Páramo, quien en estos años trabajó en series como La máscara negra (1982) o el film El rey y la reina (1986).

Además de todos ellos habría que destacar al oscense Antonio Artero (Trágala perro, 1981); al zaragozano Alejo Lorén (en el ámbito del cortometraje rodó en 1980 la serie Historia de Aragón en cinco capítulos y, adentrándose en el formato del video, las cintas ¡Plata, Plata, Plata! sobre el «tubo» zaragozano y el famoso café cantante, o Zaragoza, casco viejo, 1980, ¡Caray con la viejecita!, 1981, Caspe, de sol a sol y Caspe, mar de Aragón, 1988); o al turolense José Miguel Iranzo quien recaló en el mundo del cine en 1985 con el cortometraje Mayumea, codirigido con Víctor Lope, primer título de la firma turolense Estela Producciones de Imagen, que se dedicó a los más diferentes géneros, estilos y soportes (documental, publicidad, películas institucionales e

6 Sobre este panorama son imprescindibles las obras de Manuel Palacio. Ver: PALACIO, M. (ed.), El cine y la transición política en España (1975-1982), Madrid, Biblioteca Nueva, 2011; PALACio, M., La televisión durante la Transición española, Madrid, Cátedra, 2012 y PALACIO, M. (ed.), Las imágenes del cambio. Medios audiovisuales en las transiciones a la democracia, Madrid, Biblioteca Nueva, 2013, entre otras.

7 No olvidemos también que estamos en la gran época de la presencia de Goya en la TV española. Ver: Lazaro Sebastian, F. J. y SAnz FerReruela, F., Goya en el audiovisual. Aproximación a sus constantes narrativas y estéticas en el ámbito cinematográfico y televisivo, Prensas de la Universidad de Zaragoza, Zaragoza, 2017, pp. 122-128 y 194-205.

8 Aunque publicados en los años setenta, para el panorama de los cineastas aragoneses son imprescindibles las obras de Manuel Rotellar dedicadas a este ámbito. Ver: RotelLAR, M., Cine aragonés, Zaragoza, Cineclub Saracosta, 1970; RotelLaR, M., Aragoneses en el cine español. II jornadas Culturales, Zaragoza, Ayuntamiento de Zaragoza, 1971; RotelLAR, M., Aragoneses en el cine III, Zaragoza, Ayuntamiento de Zaragoza y Cine Club Saracosta, 1972; RotelLAR, M., Aragón en el Cine. IV Jornadas Culturales, Zaragoza, Ayuntamiento de Zaragoza, 1973 y RotelLAR, M., Aragoneses en el cine, I Ciclo de Autores Aragoneses organizado por el cineclub de la Sociedad Mercantil y Artesana, VII Semana Cultural, Barbastro, 1974. Ver asimismo: PEREZ, P. y HeRnANDEZ, J., Directores aragoneses en el cine español: de los pioneros a la vanguardia, Teruel, Semana Internacional de Cine 1991; PEREZ, P. y HERnANDEZ, J., Diccionario de aragoneses en el cine y el video (1896-1994), Zaragoza, Mira Editores, 1994; SANCHEZ VIDAL, A., Realizadores aragoneses, Zaragoza, Caja de Ahorros de la Inmaculada de Aragón (CAI), 1999; AlarCon, L. A. (coord.), Actas de las II Jornadas sobre Historia del Cine en Zaragoza: Directores zaragozanos, Zaragoza, Ayuntamiento de Zaragoza, 2005. 
industriales, tanto en cine como en vídeo) para configurar una de las filmografías más sólidas del audiovisual aragonés. Su trayectoria prosiguió con varios trabajos en Súper-8 y el mediometraje Ruido de alas (1986), antes de convertirse en realizador de la televisión por cable turolense Canal 1 y director de programas documentales institucionales y privados. ${ }^{9}$

Más allá de estos y algunos otros cineastas de origen aragonés que trabajaron en la década de los ochenta, cabe señalar la presencia de algunas otras personalidades que, sin ser realizadores, trabajaron en la industria fílmica por aquellos años. Uno de ellos, fue el prolífico actor Fernando Sancho, que todavía entonces se prodigaba por el cine español en títulos como las últimas películas del ya recalcitrante Rafael Gil (Las autonosuyas, 1983), o en otras cintas como Invierno en Marbella (José Luis Madrid, 1983) 1919, crónica del alba (Antonio J. Betancor, 1983), La vaquilla (Luis García Berlanga, 1985) o en las series de TVE Ramón y Cajal o La huella de un crimen; asimismo puede citarse el caso de Raúl Artigot quien, como director de fotografía, en sus últimos trabajos participó en películas destacadas de estos años como La plaza del diamante (Francesc Betriú, 1982), Juana la loca...de vez en cuando (José Ramón Larraz, 1983) y Requiem por un campesino español (Francesc Betriú, 1985); y otro ejemplo muy destacado fue sin duda el prolijo trabajo de Antón García Abril en el ámbito de la composición de bandas sonoras de series de TV y de películas, entre las que, en estas fechas, sin duda destacó la de Los santos inocentes (Mario Camus, 1984).

Un panorama este que certifica en definitiva cómo, a la altura de los años ochenta, nuestra región seguía siendo cuna de destacados miembros del panorama audiovisual español, tanto cuantitativa, como cualitativamente.

\section{LA PRESENCIA DEL CINE AMATEUR Y EL MOVIMIENTO CINECLUBÍSTICO: RENOVACIÓN GENERACIONAL Y NUEVOS FORMATOS}

Más allá del trabajo de estos cineastas aragoneses fuera de Aragón, la debilidad de la producción cinematográfica profesional radicada en nuestro suelo, se vio en parte contrastada por la fortaleza que todavía mantenía el cine amateur y por otro fenómeno crucial para entender este panorama que fue el

9 http://www.enciclopediaaragonesa.com/voz.asp?voz_id=7192\&tipo_busqueda $=1 \&$ nombre=iranzo\&categoria _id $=\&$ sub categoria_id=\&conImagenes $=($ fecha de consulta: 10-VIII-2019) . 
desarrollo del video como formato básico, que tuvo lugar sobre todo en Zaragoza en aquellos años ochenta. ${ }^{10}$

Bien es cierto que en esta década fallecieron tempranamente dos de los grandes adalides del panorama cultural zaragozano, y en especial del cine amateur, que fueron Manuel Rotellar (1984) y José Luis Pomarón (1987), dejando huérfano este ámbito, en un momento en el que estaba teniendo lugar la incorporación de una nueva generación de cineastas aficionados, responsables de una ingente cantidad de títulos, de un alto nivel de calidad en muchos casos, todos ellos realizados al margen de la producción industrial y profesional.

En ese sentido, ya desde los últimos años setenta se venía viviendo una época de gran esplendor para el cine amateur y aficionado aragonés, tanto en Zaragoza, como en Huesca y Teruel, heredero aún de las «glorias» que este formato había cosechado (apenas igualado a nivel nacional ni siquiera por la actividad de las grandes capitales como Madrid y Barcelona) en las décadas precedentes de los cuarenta, cincuenta y sesenta. No olvidemos que a esas alturas, todavía se mantenía vivo el Festival de Cine Amateur e Independiente de Zaragoza, ${ }^{11}$ mientras el movimiento cineclubista (germen indudable del cine aficionado en esta capital) luchaba por mantener su vigencia. Así, el Cineclub Saracosta, del Club Cine Mundo (heredero del gran Cineclub de Zaragoza, cabeza de todo este movimiento desde 1945) permanecía activo hasta 1977, viviendo sus últimos momentos de esplendor, organismo que ya desde 1978 fue sustituido por el Cineclub Gandaya, capitaneado por Alberto Sánchez Millán, y que mantendría una actividad cultural modélica en Zaragoza a lo largo de toda la década de los ochenta y hasta principios de la siguiente.

En el ámbito de la producción de cine independiente, ${ }^{12}$ casi siempre en formato de $8 \mathrm{~mm}$., podemos citar en los años ochenta a personalidades como Pedro Aguaviva (destaca su homenaje al ferrocarril en el documental Raíles de

10 Para este capítulo ver los trabajos de Francisco Javier Lázaro Sebastián y entre ellos: LAZARO SEBASTIAN, F. J., «Panorámica en torno al cine amateur en Aragón: desde sus orígenes hasta los años ochenta», en Ruiz Rojo, J. A. (coord.), En torno al cine aficionado. Actas del Encuentro de Historiadores, Guadalajara, Diputación Provincial de Guadalajara, Servicio de Cultura y Centro de la Fotografía y de la Imagen Histórica de Guadalajara, 2002, pp. 161-188.

11 Sobre este tema ver: ALARCON SIERRA, L. A., «El Festival de cine amateur de Zaragoza (1962-1976): una aproximación», en RuIz Rojo, J. A. (coord.), Actas del III Encuentro de Historiadores. Terceras Jornadas de Cine de Guadalajara, Guadalajara, Diputación Provincial de Guadalajara Centro de la Fotografía y la Imagen Histórica de Guadalajara, 2005, pp. 135-159.

12 Para este capítulo es fundamental SANCHEZ Millan, A., Cine amateur e independiente en Aragón, Zaragoza, Cineclub Gandaya, reeditado por la Institución Fernando el Católico, 2019. 
acero, 1980, y su incursión en la ficción a partir de Hacia el final del viaje, 1981); Julio Alvar y sus documentales etnográficos como Dances de Santa Orosia (Yebra de Basa), 1981, Semana Santa (Monreal del Campo), 1982, o La morisma (Aínsa), 1983, entre multitud de títulos rodados en España y Latinoamérica; algunos trabajos del gran fotógrafo Pedro Avellaned, el menos conocido Juan Burillo, autor de apuestas arriesgadas e interesantes como Color de atardecer (1980) y Queridas costureras (1981); Santiago Chóliz, realizador tanto de documentales como de ficción, del que por estos años tuvieron repercusión títulos como Frontera (1980), La leyenda de Flanagan (1981) y Otra vez primavera (1982); los interesantes ejercicios plásticos del pintor Eduardo Laborda (El regreso, 1984, Márgenes, 1984, Vino en carne mortal a Zaragoza, 1985); y por supuesto los hermanos Sánchez Millán, muy activos en los sesenta y setenta, y que en los ochenta aún ruedan algunos documentales como Aragón nuestro (1981).

Y más allá de los autores individuales, desde finales de los setenta y a lo largo de los ochenta se formaron toda una serie de grupos de «cineístas» a los que unió una vocación de trabajo en común, entre los que conviene resaltar el Grupo Andanzas, originado en el seno de la Real Sociedad Fotográfica de Zaragoza en 1980, fundado por Juan Carlos del Río y Armando Serrano, que rodaron Andanzas (1980), Homenaje (1982), Luz de atardecer (1983) o Ritual de Pazuzú (1985).

También en 1980 surgió en Zaragoza el grupo Cineceta, de donde salieron, entre otras muchas cintas, Martes 17 a las 9 y media (1981), Color de luz (1985) o Su último suspiro (1985), a cargo de diversos autores entre los que destacaron José Antonio Vizárraga o Juan Isidro Gotor.

En 1977 comenzó su andadura Chiribito Films, formado por Carlos Pomarón, Juan José Lombarte, Joaquín Maicas y Jesús R. Ferrer, responsables de títulos como Pirenaica (1980), Pabostría (1981), Logaritmo (1981) o Asimetría (1982).

Finalmente, también los miembros de la Tertulia Cinematográfica Aragonesa rodaron algunas obras como Susurros (1981), El botero (1982), Muerte en Calanda (1983) o La contradanza de Cetina (1984), llevados a cabo por personalidades de la talla de José Luis Pomarón, Santiago Choliz o Alberto Sánchez.

Por aquella época, incluso algunos organismos educativos como el Instituto de Ciencias de la Educación (ICE) de la Universidad de Zaragoza, produjeron, sin ningún afán comercial más allá de su uso como herramienta 
pedagógica, una amplia serie de cortometrajes didácticos, de muy diversa índole, auspiciados por el profesor Agustín Ubieto con el título de Comprender Aragón.

Y en Teruel se crearon por aquellos años otros dos destacados grupos de cineastas aficionados: La estética moderna PC, fundado en 1980 gracias a J. Félix Serna y Ángel Gonzalvo, autores, entre otros, de cortometrajes como ¿Qué es lo que más quieren las mujeres? (1981), El fotograma (1982) o Chupe como en América, chupe a la americana (1984); y San-Gría filmes, que apareció en 1981 y que rodaron obras como Que Dios nos pille confesaos (1981), Co-chinada (1982), Por el imperio (1983), Casualidad o El concurso (1984). Similar a la citada actividad del ICE, en la capital bajoaragonesa se creó el grupo de cine del Seminario de Arqueología y Etnología Turolense, que también realizaron documentales pedagógicos a partir de 1980.

Capítulo aparte requiere en esta época el extraordinario desarrollo del documental etnográfico, del que ya hemos visto algunos ejemplos, rodado todavía en cine al principio, pero poco a poco cada vez más frecuentemente en vídeo. En este punto es indispensable el trabajo de Eugenio Monesma, quien precisamente en los años ochenta dio comienzo a su extensa producción documental (a caballo entre su naturaleza original amateur y más tarde su vocación directamente profesional), consagrada a dar a conocer la riqueza etnográfica, histórica y artística aragonesa, a través de sus reportajes sobre multitud de personajes históricos y sobre todo municipios aragoneses, así como sobre las costumbres, oficios perdidos, folclore, indumentaria, y manifestaciones populares, artísticas y, en general, culturales de Aragón.

\section{EL ÁMBITO DE LA EXHIBICIÓN}

En otro orden de cosas, y ya en el ámbito de la exhibición, no puede dejar de señalarse que, como acertadamente señaló hace ya muchos años Agustín Sánchez Vidal, la década de los ochenta fue, en este terreno, la de la gran crisis, ${ }^{13}$ marcada por el masivo cierre de salas de cine. Sólo en el caso de Zaragoza, tal y como señala Amparo Martínez, ${ }^{14}$ entre 1979 y 1985 cerraron en la ciudad dieciséis salas de cine, desapareciendo por completo los cines de barrio, aunque desde el punto de vista cuantitativo esta merma se vio

13 SANCHEZ VIDAL, A., El siglo de la luz. Aproximaciones a una cartelera II. De Gilda a La red (1947-1996), Zaragoza, CAI, 1997, p. 13.

14 MARTinez Herranz, A., Los cines en Zaragoza. 1939-1975, Zaragoza, Elazar Ediciones, 2005, pp. 359-360. 
contrapuesta por la apertura de las multisalas de cine asociadas a los centros comerciales, a la par que fueron cobrando fuerza los primeros festivales de cine aragoneses, fundamentalmente el de Huesca, que había comenzado su andadura ya en 1973.

A pesar de todo, como recuerda Sánchez Vidal, en el momento de la aparición de Neuróptica los mayores éxitos que pudieron ver los espectadores en las salas zaragozanas fueron las ya míticas E.T., el extraterrestre (Steven Spielberg), Blade Runner (Ridley Scott), Gandhi (Richard Attenborough), Oficial y caballero (Taylor Hackford) o Tootsie (Sydney Pollack), mientras los buenos cinéfilos lloraban la muerte de Luis Buñuel.15

De cualquier forma, y aunque las salas comerciales cerraban por doquier, hay que señalar que el ámbito de la exhibición en Zaragoza siguió ofreciendo múltiples posibilidades al espectador inquieto. En primer lugar gracias a la actividad de los cineclubs, a los que ya hemos hecho referencia, y que hasta mediados de la década vivieron aún sus últimos momentos de esplendor. No olvidemos que además de los institucionales, muchos colegios mayores, residencias universitarias y hasta centros parroquiales, mantuvieron abiertos en los ochenta más de una docena de cineclubs privados. De entre todos ellos destacó desde luego el Gandaya, a cuya cabeza estuvo siempre su director, Alberto Sánchez Millán, cinéfilo y cineclubista desde su infancia, fotógrafo y cineasta amateur junto con su hermano Julio, e inquieto activista cultural. Entre las programaciones más interesantes del Gandaya en esos años, hay que resaltar el homenaje a Segundo de Chomón, que contó con una mesa redonda en torno a su figura, y el ciclo dedicado a los cineístas amateur aragoneses, con sesiones monográficas sobre Pedro Avellaned, Juan Burillo, el Grupo Eisenstein (compuesto por José Luis Rodríguez Puértolas, Mariano Baselga, Fernando Gracia, Fernando Alonso, Pedro Marqueta, Alberto Sánchez y Emiliano Puértolas, entre otros), Fernando Manrique, Manuel Labordeta, Luis Pedro Pellegero, José Luis Pomarón, Alberto y Julio Sánchez Millán, Miguel Vidal Cantos, José María Sesé Marzo, etc. De cada sesión se editaba un boletín informativo, heredero de los boletines del cineclub de Zaragoza y el Saracosta, referencias bibliográficas todas ellas fundamentales, a la par que poco estudiadas, sobre muchos temas como el cine amateur aragonés.

Y en ese mismo ámbito cabe señalar que a comienzos de los años setenta, y disgregándose de la catalana-balear, se creó la vocalía aragonesa

15 SANCHEZ Vidal, A., op. cit., pp. 330-333. 
de la Federación Española de Cine Clubs, luego llamada Confederación de Cine Clubs del Estado Español. A partir de 1985 pasó a denominarse Federación Aragonesa de Cine Clubs, y su principal cometido fue facilitar la programación de los diferentes organismos asociados de la comunidad $\mathrm{y}$, muy especialmente, llevar a cabo las Campañas de Promoción Cinematográfica en el ámbito rural. ${ }^{16}$

Por otro lado, y ofreciendo nuevas posibilidades para los aficionados y estudiosos del cine en Zaragoza, conviene recordar que, precisamente cuando Neuróptica inicia su andadura, hacía poco tiempo que funcionaba la Filmoteca de Zaragoza, con Manuel Rotellar a la cabeza. Un organismo de gestión municipal -a diferencia de la mayoría de las filmotecas españolas que dependen de los gobiernos autonómicos- que, desde 1981 y hasta la actualidad, viene desarrollando su tarea, por un lado en el terreno de la exhibición, organización de ciclos, conferencias, publicaciones y exposiciones, y por otro en los campos de la investigación, conservación y difusión del patrimonio, fundamentalmente cinematográfico, de nuestra región.

De igual modo en esos años se celebraron las populares Muestras de cine de estreno, organizadas de nuevo por Manuel Rotellar para el Ayuntamiento de Zaragoza, desde la primavera de 1981. La primera Semana, y también las dos que le siguieron (1982 y 1983) se celebraron en el Cine Palafox, con mucho éxito de público. El programa se componía de películas inéditas en Zaragoza, como La ciudad de las mujeres (Federico Fellini, 1979), Vestida para matar (Brian de Palma, 1980), Gary Cooper que estás en los cielos (Pilar Miró, 1980), Basket Music (Gilbert Moses, 1980), Madame Petit (Christian Gion, 1980) y Kagemusha, la sombra del guerrero (Akira Kurosawa, 1980). Además, en el marco de esas jornadas se proyectó en el Centro Pignatelli un ciclo de cine alemán, tanto clásico como moderno, con cintas como Tartufo o el hipócrita (F. W. Murnau, 1925), La escalera de servicio (Leopold Jessner, 1921), Las aventuras del Príncipe Achmed (Lotte Reiniger, 1926), El vaso de agua (Helmut Kautner, 1960), La estirpe de Odin (Rolf Thiele, 1964) o ¿Por qué le da el ataque de locura al señor R? (Rainer Werner Fassbinder, 1969).

16 http://www.enciclopedia-

aragonesa.com/voz.asp?voz_id=13407\&tipo_busqueda=1\&nombre=cine \%20aragon\&categoria _id=\&subcategoria_id=\&conImagenes=, (fecha de consulta: 10-VIII-2019). 
La segunda Muestra, en 1982, se celebró con igual éxito popular que la inicial. En el amplio vestíbulo del Cine Palafox fue instalada una exposición de carteles de películas polacas (el año anterior hubo una exitosa muestra de prospectos de cine) y algunas de las películas exhibidas fueron La mujer de al lado (François Truffaut, 1971), To er mundo e güeno (Manuel Summers, 1982), Rayos X (Boaz Davidson, 1981), Faraón (Jerzy Kawalerowicz, 1966), Un viaje alucinante al fondo de la mente (Ken Russell, 1980) y Ordinaria locura (Marco Ferreri, 1981). Asimismo se desarrolló una retrospectiva sobre cine francés, en el Centro Pignatelli, en homenaje a Jacques Tati y Robert Bresson, con sus películas más importantes.

La tercera Muestra de Cine de Estreno se celebró en 1983, con las películas: Los unos y los otros (Claude Lelouch, 1981), El reto del Samurái (John Frankenheimer, 1982), Y del seguro... líbranos, Señor! (Antonio del Real, 1983), Hablamos esta noche (Pilar Miró, 1982), Sangre y Arena (Rouben Mamoulian, 1941) y El Curso de 1984 (Mark Lester, 1982). La sección cultural tuvo en esta edición singular importancia, pues se le rendió un homenaje a Antón García Abril. Las sesiones se celebraron en el Colegio Mayor Virgen del Carmen, se contó con la asistencia del maestro y se proyectaron cuatro películas cuya banda sonora fue compuesta por el músico turolense: El rostro del asesino (Pedro Lazaga, 1965), El crimen de Cuenca (Pilar Miró, 1979), Los días del pasado (Mario Camus, 1977) yEl perro (Antonio Isasi, 1976). Finalmente cabe señalar que se publicó una monografía sobre Antón García Abril y, al igual que en pasadas ediciones, se organizó en el vestíbulo del Cine Palafox una exposición, en esta ocasión, de bibliografía cinematográfica, en cinco grandes vitrinas, con más de un centenar de libros, clasificados por géneros, cinematografías nacionales, mitos y grandes productoras.

Del mismo modo debe recordarse la celebración, por aquellas fechas, de la Semana de Cine Español, organizada por el Aula de Cine (en marcha desde 1978) de la Universidad de Zaragoza, con motivo de la conmemoración del IV centenario de esta institución. Del 21 al 26 de marzo de 1983 se celebraron en el salón de actos del ICE seis sesiones cuyo contenido se estableció así: «De la postguerra a los años sesenta», con la proyección de $E l$ Clavo (Rafael Gil, 1944), y un debate en mesa redonda en el que intervinieron Rafael Gil, Alfredo Mayo y Manuel Rotellar; «Años sesenta: La Escuela de Cine»; «Años sesenta: La Escuela de Barcelona», proyectándose filmes de José María Nunes, con asistencia del propio realizador y de José María Forn y Román Gubern; «Los años setenta: Los nuevos realizadores»; «Cine maldito, ¡Maldito cine!», con la película Kargus (J. Miñón, 1981); y como acto de 
clausura, una selección de cortometrajes con la presencia de diversos realizadores y actores. ${ }^{17}$

\section{EPÍLOGO: ARAGÓN TIERRA DE CINE}

No cabe duda de que Aragón ha vivido siempre un particular idilio con el cine que ha adoptado otras muy diversas manifestaciones. En primer lugar como escenario de rodaje, pues no en vano han sido muchos los directores de cine, tanto españoles como extranjeros, que se han sentido atraídos por la belleza, diversidad y capacidad evocadora de los pueblos y paisajes aragoneses, y han rodado aquí sus películas desde los inicios del cine hasta nuestros días. No olvidemos que, solamente en los años ochenta se filmaron en nuestro territorio obras tan representativas (algunas ya citadas) y tan dispares como La vaquilla (Luis García Berlanga, 1985), Tata mía (José Luis Borau, 1986) o Tierra y libertad (Ken Loach, 1987), por citar algunas. ${ }^{18}$

Y si, evidentemente, los rodajes de cine de ficción en Aragón contaron con personalidades tan destacadas como las que hemos citado, hay que recordar también que en los ochenta, recalaron por nuestra región algunos de los últimos representantes de un formato, tan importante como poco conocido, como fue el cortometraje documental, de amplia presencia en el panorama fílmico español entre los años cuarenta y setenta y ya algo más minoritario en la década que nos ocupa. Sin embargo, cineastas como César Fernández Ardavín, desde su productora Aro Films, produjo en los años ochenta varias cintas dedicadas a Aragón y a los aragoneses ilustres, particularmente a Goya. Así pueden citarse La mujer de Goya (1975), Un lugar llamado Alquézar (1980), Los caprichos de Goya (1980), Un lugar llamado Daroca (1982) y Un lugar llamado Albarracín (1982).

De igual modo deben señalarse algunos otros fenómenos que vinculan Aragón con el ámbito cinematográfico en esta década, como por ejemplo la proliferación de biografías fílmico-televisivas sobre personajes aragoneses, a las que ya hemos aludido, o también la adaptación al cine de algunas obras literarias de autores aragoneses, como Ramón J. Sender, entre

17 http://www.enciclopedia-

aragonesa.com/voz.asp?voz id=13407\&tipo busqueda=1\&nombre=cine\%20aragon\&categoria id=\&subcategoria id=\&conImagenes $=$, (fecha de consulta: 10-VIII-2019).

18 Sobre este punto pueden consultarse: SANZ FERRERUELA, F., «De paisajes y baturros. La imagen de Aragón y los aragoneses en el audiovisual español», Archivo de Filología Aragonesa, vol. 69, Zaragoza, Institución Fernando El Católico, 2013, pp. 141-167, y el documental Aragón rodado (Vicky Calavia, 2014). 
las que destaca el Réquiem por un campesino español vertido a la pantalla por Frances Betriu en 1985.

Por último es de justicia reseñar que en los años ochenta estaba empezando a afianzarse la historiografía del cine en Aragón de la mano del profesor Agustín Sánchez Vidal, quien a lo largo de la década fue asentando las bases historiográficas, y muchas líneas de investigación, que todavía permanecen activas hoy en el seno de la Universidad de Zaragoza, a través de los, ya en ese momento y todavía hoy, indispensables estudios monográficos sobre los cineastas aragoneses, y de forma muy especial, sobre el universal Buñuel. ${ }^{19}$

19 En especial SAnchez Vidal, A., Obra literaria. Luis Buñuel, Zaragoza, Heraldo de Aragón, 1982 y SANCHEZ VidAL, A., Luis Buñuel: obra cinematográfica, Madrid, Ediciones JC, 1984. 